\title{
ROLE OF MIFEPRISTONE IN MEDICAL MANAGEMENT OF UTERINE FIBROID
}

\author{
Shradha ${ }^{1}$,Archana Kumari², P. B. Sahay ${ }^{3}$
}

1 Junior Resident, Department of Obstetrics \& Gynaecology, Rajendra Institute of Medical Sciences, Ranchi, Jharkhand. ${ }^{2}$ Assistant Professor, Department of Obstetrics \& Gynaecology, Rajendra Institute of Medical Sciences, Ranchi, Jharkhand. 3 Professor and HOD, Department of Obstetrics \& Gynaecology, Rajendra Institute of Medical Sciences, Ranchi, Jharkhand.

\begin{abstract}
BACKGROUND: Uterine leiomyoma is the most common benign tumour of uterus affecting women of reproductive age group and accounting for most common indication of hysterectomy in India. Effective medical treatment option can prevent hysterectomy related morbidity.
\end{abstract}

MATERIALS AND METHODS: A total of 50 women with symptomatic leiomyoma and asymptomatic with uterine volume $>160 \mathrm{cc}$ and fibroid size $>2.5 \mathrm{~cm}$ were included in the study. $20 \mathrm{mg}$ /day mifepristone was given to them over period of 3 months. Follow up was done at 1, 3 and 6 months of starting treatment. At each visit patients were evaluated for symptomatic improvement of menorrhagia, dysmenorrhoea and ultrasound for myoma volume, haemogram was done. Endometrial biopsy was done at the beginning of therapy, $3^{\text {rd }}$ month and at end of treatment.

RESULTS: At the beginning of study, all patients had menorrhagia. At 3 months, $80 \%$ developed amenorrhea and $20 \%$ scanty menses. At 6 months, 56\% had scanty menses and 38\% had normal menses but none had menorrhagia. 50\% of patients had dysmenorrhoea at the beginning of study with severe dysmenorrhoea in $36 \%$ of cases. Only $10 \%$ of patients at 3 months and $14 \%$ at 6 months had dysmenorrhoea. Improvement in haemoglobin percentage from 9.6 gram $\%$ to 10.8 gram $\%$ at 3 months of therapy. The reduction in mean uterine volume was $12.28 \%$ after 1 month, $26.95 \%$ after 3 months and $11.13 \%$ at end of 6 months, as compared to pre-treatment level. Fibroid volume decreased by $14.34 \%$ after 1 month ,29.8\% after 3 months and $24.98 \%$ at end of 6 months, as compared to pretreatment level. At the end of 3 months, $50 \%$ of patients experienced no side effect. Rest $50 \%$ experienced minor side effects like nausea (8\%), hot flushes (4\%), liver dysfunction as evidenced by mild increase in transaminase (8\%) and simple endometrial hyperplasia in $30 \%$. Follow up of these patients at 6 month i.e., 3 months after stopping the drug does not show any evidence of persistence of these effects.

CONCLUSION: 20mg mifepristone produces reduction in myoma size, uterine volume and improvement of symptoms like menorrhagia and dysmenorrhoea. It is administered orally, cost effective and is well tolerable with less side effects.

KEYWORDS: Amenorrhoea, fibroid, leiomyoma, mifepristone, uterine.

HOW TO CITE THIS ARTICLE: Shradha, Archana Kumari,P. B. Sahay. "Role of Mifepristone in Medical Management of Uterine Fibroid". Journal of Evolution of Medical and Dental Sciences 2015; Vol. 4, Issue 88, November 02; Page: 15325-15329,

DOI: $10.14260 /$ jemds/2015/2179.

INTRODUCTION: Uterine leiomyoma is the most common benign tumour of uterus affecting $20 \%$ of all women of reproductive age group. ${ }^{1}$ and leading to $1 / 3$ rd of all gynaecological admissions in hospitals. ${ }^{2} 40 \%$ of these patients symptoms severe enough to warrant therapy. ${ }^{3}$ Leiomyoma uteri is the most common indication for hysterectomy and accounts for $40 \%$ of all hysterectomies in premenopausal women. ${ }^{4}$ Although hysterectomy is the only definitive cure for leiomyoma, it has its own morbidity and long term complications. Thus, medical management and minimal invasive techniques are gaining popularity now a days.

These are highly beneficial for young unmarried women who want to avoid surgery, in women having comorbid conditions contraindicating surgery and in perimenopausal women in whom fibroid volume will regress after menopause. Amongst medical therapy, GnRH agonist which is given as a monthly injection has shown to

Financial or Other, Competing Interest: None.

Submission 29-09-2015, Peer Review 30-09-2015,

Acceptance 20-10-2015, Published 31-10-2015.

Corresponding Author:

Dr. Shradha, W/o. Dr. Prashant Upadhyay, Flat No. 2, Block A,

Ambey's Villa, H. E. School Road, Hirapur, Dhanbad,

Jharkhand-826001.

E-mail: shradha21pmch@gmail.com

DOI: $10.14260 /$ jemds/2015/2179. decrease size of fibroid by $35 \%$ and total uterine volume by $30 \%$ after 6 months of therapy. ${ }^{5} \mathrm{GnRH}$ antagonist has rapid action and accounts for $29 \%$ decrease in fibroid volume by 3 weeks. ${ }^{6}$

However, these are not widely acceptable as these are costly, administered parent rally and associated with severe hypo estrogenic symptoms and bone loss after prolonged use.7 Moreover, cessation of treatment leads to regrowth of myoma within 4 to 6 months. 7 Danazol decreases uterine volume by 18 to $23 \%$ but is associated with androgenic side effect and liver dysfunction.8 LNG-IUS is effective in decreasing fibroid related menorrhagia in $85 \%$ cases over 3 months. 9

But these can be used only when uterine size is $<12$ weeks and uterine cavity is normal. Several studies has shown that there is no change in uterine volume with LNG-IUS and expulsion rate is higher amongst patient with fibroid.10 Uterine artery embolisation decreases size of fibroid, causes symptomatic relief but there is risk of premature ovarian failure and uterine synechiae. ${ }^{11}$

MRgFUS is a new FDA approved non-invasive technique for treatment of uterine myoma. It causes significant improvement of symptoms, decreases fibroid volume by $15 \%$ over 6 months and does not compromise future fertility carrier of patient. ${ }^{12}$ But it is out of reach of most patients due to high cost of treatment and availability at few tertiary centres only. 
Both estrogen and progesterone plays a vital role in growth of uterine fibroid. In fibroid tissue, as compared to normal myometrium has higher concentration of aromatase enzyme leading to increased local production of estradiol. ${ }^{13}$

Also there is increased expression of progesterone receptor $A$ and $B$ in fibroid tissue and highest mitotic count are found in fibroid tissue at peak of progesterone production. ${ }^{14}$ Thus, antiprogesterone like mifepristone, uripristal, asoprisnil and CDB-2914 came under study. ${ }^{15}$

Mifepristone is a progesterone receptor modulator with primarily antagonistic properties. It binds strongly to endometrial progesterone receptors, minimally to estrogen receptors and upregulates androgen receptors. ${ }^{16}$ Prospective randomised control trial has shown mifepristone to decrease uterine volume by $48 \%$ after 6 months of therapy. ${ }^{17}$

The aim of my study was to highlight the role of mifepristone as a cost effective and safe medical therapy for uterine leiomyoma and also as an alternative to surgery.

MATERIAL AND METHODS: This prospective randomized control trial was conducted on 50 patients attending Outpatient Department of Obstetrics \& Gynaecology Rajendra Institute of Medical Science, Ranchi over period of May 2013 to May 2014. Ethical approval from RIMS ethical committee was taken. Informed consent were taken from patients involved in the study group after screening them according to inclusion and exclusion criteria.

Inclusion criteria of my study are women of reproductive age group, symptomatic fibroid, asymptomatic patients with USG showing uterine volume $\geq 160 \mathrm{cc}$ or fibroid size $\geq 2.5 \mathrm{~cm}$ and those women who agreed to use nonhormonal method of contraception throughout the study period to prevent pregnancy. Exclusion criteria includes fibroid $>12$ weeks size, atypical endometrial hyperplasia, associated pelvic pathology, pregnant women and lactating mother and those desirous of pregnancy, those who have used hormonal medication for fibroid or hormonal contraception within last 3 months or having any contraindication to use of mifepristone.

The subjects were given $20 \mathrm{mg}$ mifepristone preparation once daily for 3 months. It comes in $200 \mathrm{mg}$ tablets, so it was crushed and divided into 10 equal doses for daily administration. They were followed at 1 month, 3 month while on therapy and then at 6 months i.e. 3 months after stopping therapy. At each visit, clinical symptoms, uterine volume, fibroid volume, change in hemoglobin level and side effects were assessed. Endometrial biopsy was done at beginning of study, at $3^{\text {rd }}$ and $6^{\text {th }}$ month.

\section{Evaluation Criteria:}

\begin{tabular}{|c|c|}
\hline None & Amenorrhea \\
\hline Scanty & $\begin{array}{c}\text { Less than normal bleeding occurs during } \\
\text { menstruation }\end{array}$ \\
\hline Average & $\begin{array}{c}\text { Normal amount of blood loss occurs during } \\
\text { menstrual cycle }\end{array}$ \\
\hline Heavy & Patient has menorrhagia \\
\hline \multicolumn{2}{|c|}{$\begin{array}{c}\text { Table 1: Symptomatic assessment } \\
\text { of menstrual blood loss }\end{array}$} \\
\hline
\end{tabular}

\begin{tabular}{|c|c|}
\hline None & No dysmenorrhoea \\
\hline Mild & Analgesic are not required \\
\hline Moderate & $\begin{array}{c}\text { Analgesic may be required, but patient can carry } \\
\text { out normal activities }\end{array}$ \\
\hline Severe & $\begin{array}{c}\text { Patient cannot carry out normal activities, always } \\
\text { require pain killers }\end{array}$ \\
\hline \multicolumn{2}{|c|}{ Table 2: Symptomatic assessment of dysmenorrhoea } \\
\hline
\end{tabular}

3. Hemoglobin percentage, LFT, RFT.

4. Ultrasound with color Doppler for:

a) Uterine volume - Calculated by Viscosmi formula: $4 / 3 \pi \mathrm{W} / 2 \times \mathrm{L} / 2 \times \mathrm{T} / 2$

Where $\mathrm{W}=$ Width; $\mathrm{L}=$ Length; $\mathrm{T}=$ Thickness

b) Fibroid volume $-4 / 3 \pi$ abc

Where $a, b$ \& $c=$ Radii of sphere.

5. Endometrial biopsy for hyperplasia

RESULTS: At the beginning of study, all patients had menorrhagia. After 1 month of therapy, none of patients had menorrhagia, 18 out of 50 had average menses, 22 had scanty menses and 10 became amenorrhic. At 3 months, 40 out of $50(80 \%)$ developed amenorrhea and 10 out of 50 (20\%) had scanty menses. At 6 months, 27 out of $50(56 \%)$ had scanty menses and 19 out of $50(38 \%)$ had normal menses but none had menorrhagia.

DISCUSSION: Mifepristone is a PROGESTERONE RECEPTOR MODULATOR with antiprogestogenic, antiglucocorticoid and weak antiandrogenic activity. It was first synthesized in 1980 by a french company Roussel Uclaf. This was the $38486^{\text {th }}$ compound synthesized by this company hence called RU 38486 or simply RU486. Its use as a treatment option of myoma was first described by Murphy et al in 1993.18 It was approved for use in India in 2002 by ICMR. Dose of mifepristone ranges from 2.5-50 mg once daily over period of 3-6 month. Lower dose is associated with good symptomatic improvement, minimal side effect but less reduction in myoma and uterine size as compared to higher dose. Other uses of drug are medical termination of pregnancy, emergency contraception, induction of labor, ectopic pregnancy, cushing syndrome, major depression with psychotic illness, glaucoma, meningioma, breast, ovarian and prostate cancer.

Mifepristone is also under trial as an antiretroviral therapy and for chronic multisystem disorder. It is contraindicated in conditions like active liver disease, renal disease, adrenal insufficiency, hemorrhagic disorders, inherited porphyria and in patients on anticoagulant or long-term corticosteroid therapy.

In the present study, $20 \mathrm{mg}$ daily dose of mifepristone was found to be effective in relieving symptoms like menorrhagia, dysmenorrhoea; improving anaemia and decreasing mean uterine volume and size of fibroid. Also it is well tolerated without having any serious side effects. Improvement in symptoms was noted as early as in the first month of therapy as also noted in other studies. 2 patient conceived after stopping treatment, indicating that fertility resumes soon after stopping the therapy.

In conclusion, it is good alternative medical therapy in preoperative period as it improves anaemia, reduce size of tumour making surgery technically easier. 
It is proved to be a reasonable choice in perimenopausal women in whom myoma regresses after menopause and in the nulliparous women who want to avoid surgery. It can also be used as a preoperative adjunct, especially in patients with severe anaemia and in large fibroid where surgery is technically difficult.

It is not used as a primary medical therapy because of recurrence of symptoms after stopping treatment. However, it has simplicity of oral administration, cost effectiveness and minimal side effects.

\section{REFERENCES:}

1. Jeffcoate's Principle of Gynaecology. Tumour of corpus uteri, $7^{\text {th }}$ Ed. p. 488-91.

2. Lesley L. Breech, John A. Rock. Leiomyomata uteri and myomectomy. Te Linde Operative Gynaecology, $10^{\text {th }}$ ed. P. 688.

3. Adamson GD. Treatment of uterine fibroid with current findings with GnRH agonists. Am J Obstet Gynaecol 1992; 166:746-51.

4. Whiteman MK, Hillis SD, Jamieson DJ,et al. Inpatient hysterectomy surveillance in united states, 2000-2004. Am J Obstet Gynecol 2008; 198:34.el-34.e7.

5. Schllaf WD, Zerhouni EA, Huth JA,et al.A placebo controlled trial of a depot gonadotrophin releasing hormone analogue leuprolide in treatment of uterine leiomyomata. Obstet Gynecol 1989; 74:856-862.

6. Flierman PA, Oberye JJ, Van der Hulst VP,et al. Rapid reduction of leiomyoma volume during treatment with the GnRH antagonist ganirelix. BJOJ 2005; 112:638-642.

7. Letterie GS, Coddington CC, Winkel CA, et al. Efficacy of a gonadotrophin-releasing hormone agonist in treatment of uterine leiomyoma: long term follow up. Feril Steril 1989;51: 951-956.

8. Delco V la Marca A, Margante G. Short term treatment of uterine fibromyoma with danazol. Obstet Gynecol 1999; 47:258-62.
9. Grigorieva V, Chen Mok M, Tarasova M, et al. Use of LNG-IUS to treat bleeding related to uterine leiomyomas. Fertil Steril 2003; 79:1194-1198.

10. Mercorio F, De Simone R, Di Spiezio Sardo A, et al. The effect of LNG-IUS in treatment of myoma related menorrhagia. Contraception 2003; 67:277-280.

11. Pron G, Cohen M, Soucie J, Garvin G. The Onterio uterine fibroid Embolization Trial Part 1. Fertil Sternil.2003; 79:1129.

12. Stevert EA, Rabinovici J, Tempany CM, et al. Clinical outcomes of focussed ultrasound surgery for treatment of uterine fibroids. Fertil Steril 2006; 85:22-29.

13. Cook JD, Walker CL. Treatment stratergies for uterine leiomyoma: the role of hormonal modulation. Semin Reprod Med 2004; 22:105-111.

14. Kawaguchi K, Fuji S, Konishi I, et al. Mitotic activity in uterine leiomyomas during menstrual cycle. Am J Obstet Gynecol 1989; 160:637-641.

15. Murphy AA, Morales AJ, Kettal LM, Yen SSC. Regression of uterine leiomyomata to the antiprogestogen RU486 dose response effect. Fertil Steril. 1995; 64:187-90.

16. Spitz IM. Clinical utility of progesterone receptor modulators and their effect on endometrium. Curr Opi Obstet and Gynecol. 2009; 21:318-24.

17. Fiscella K, Eisenger SH, Meldrum S, et al. Effect of mifepristone for symptomatic leiomyomata on quality of life and uterine size: a randomized controlled trial. Obstet Gynecol 2006; 108:1381-1387.

18. Murphy AA, Kettal LM, Morales AJ, Robert VJ, Yen SSC. Regression of uterine leiomyoma in response to antiprogestogen RU486. J Ciin Endocrinol Metab. 1993; 76:513-17.

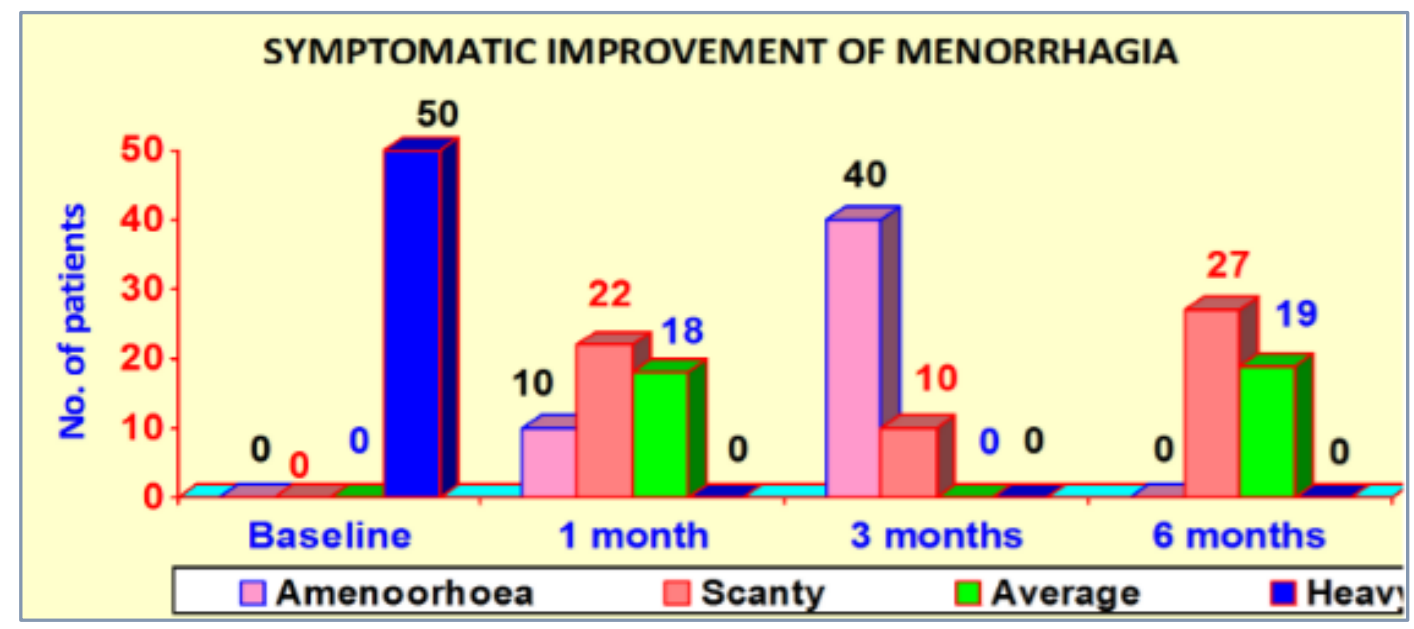

25 out of $50(50 \%)$ patients had dysmenorrhoea at the beginning of study with severe dysmenorrhoea in 18(36\%) cases. Only 5 out of $50(10 \%)$ of patients at 3 months and 7 out of $50(14 \%)$ at 6 months had dysmenorrhoea. None had severe dysmenorrhoea even up to 6 months of starting treatment. 


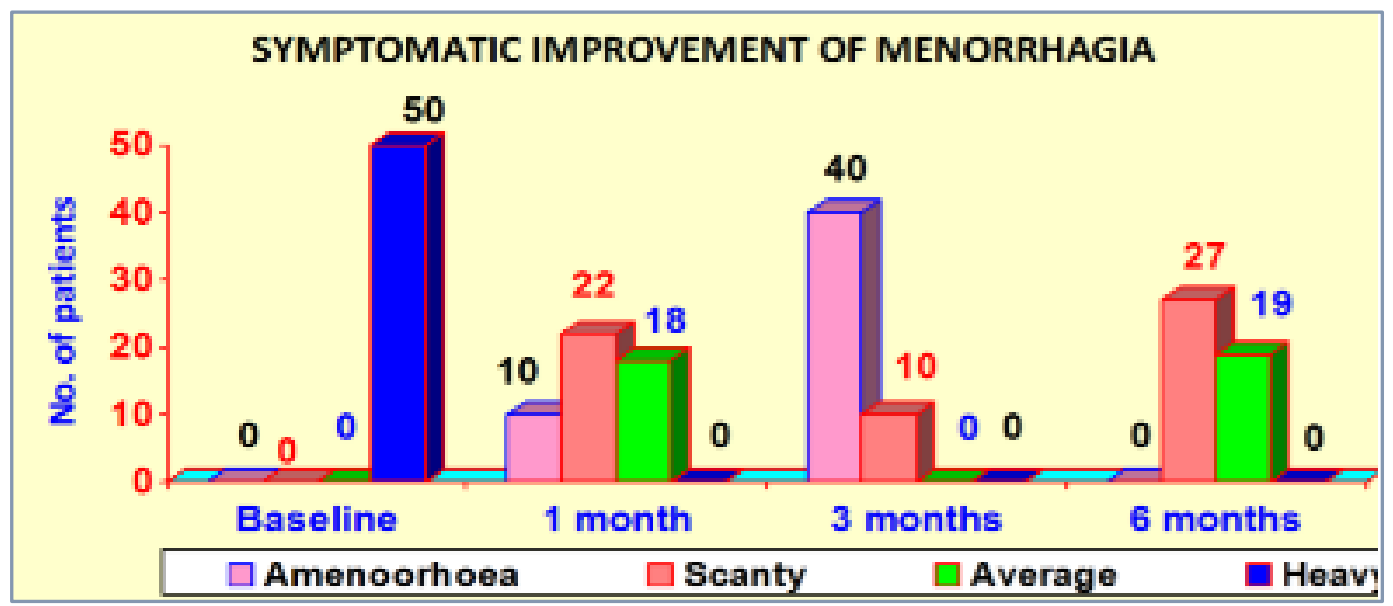

Due to improvement of menorrhagia there was significant increase in mean haemoglobin percentage from $9.6 \mathrm{gram} \%$ to $10 \mathrm{gm} \%$ at $1^{\text {st }}$ month and 10.8 gram $\%$ at $3^{\text {rd }}$ months of therapy. Mean haemoglobin level was $10.1 \mathrm{gm} \%$ at $6^{\text {th }}$ month of therapy i.e., 3 months after discontinuation of drug.

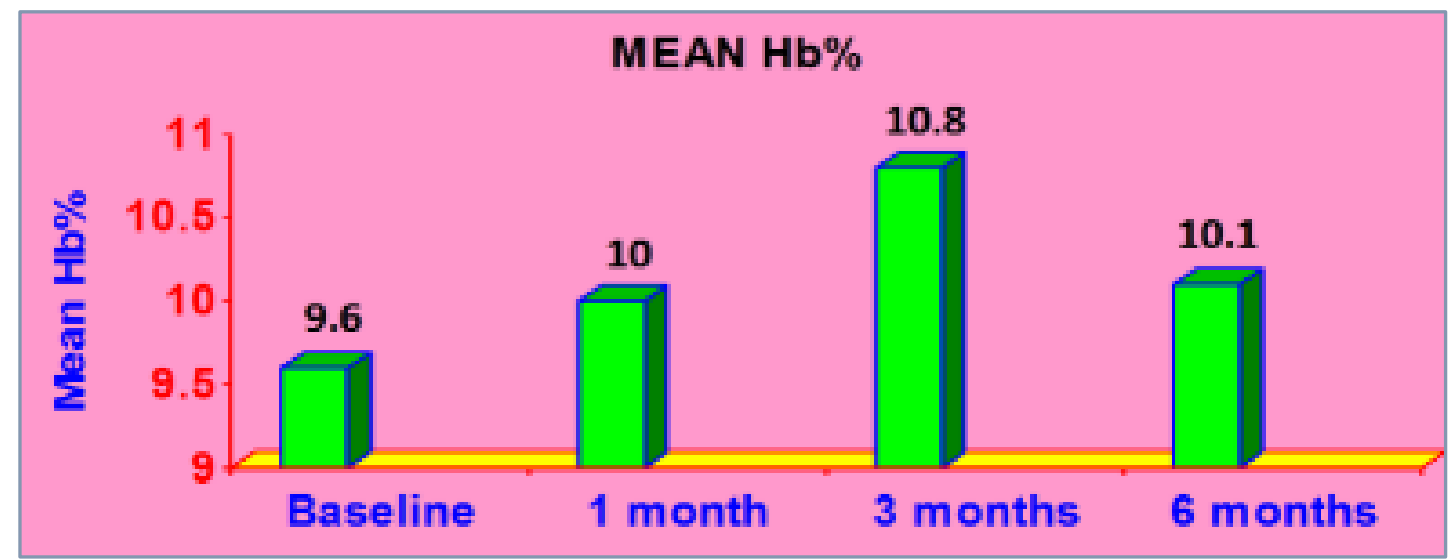

Mean uterine volume was $256 \mathrm{cc}$ at the beginning of therapy. The reduction in mean uterine volume was $12.28 \%(224.56 \mathrm{cc})$ after 1 month, $26.95 \%(187.02 \mathrm{cc})$ after 3 months and $(227.75 \mathrm{cc}) 11.13 \%$ at end of 6 months, as compared to pre-treatment level.

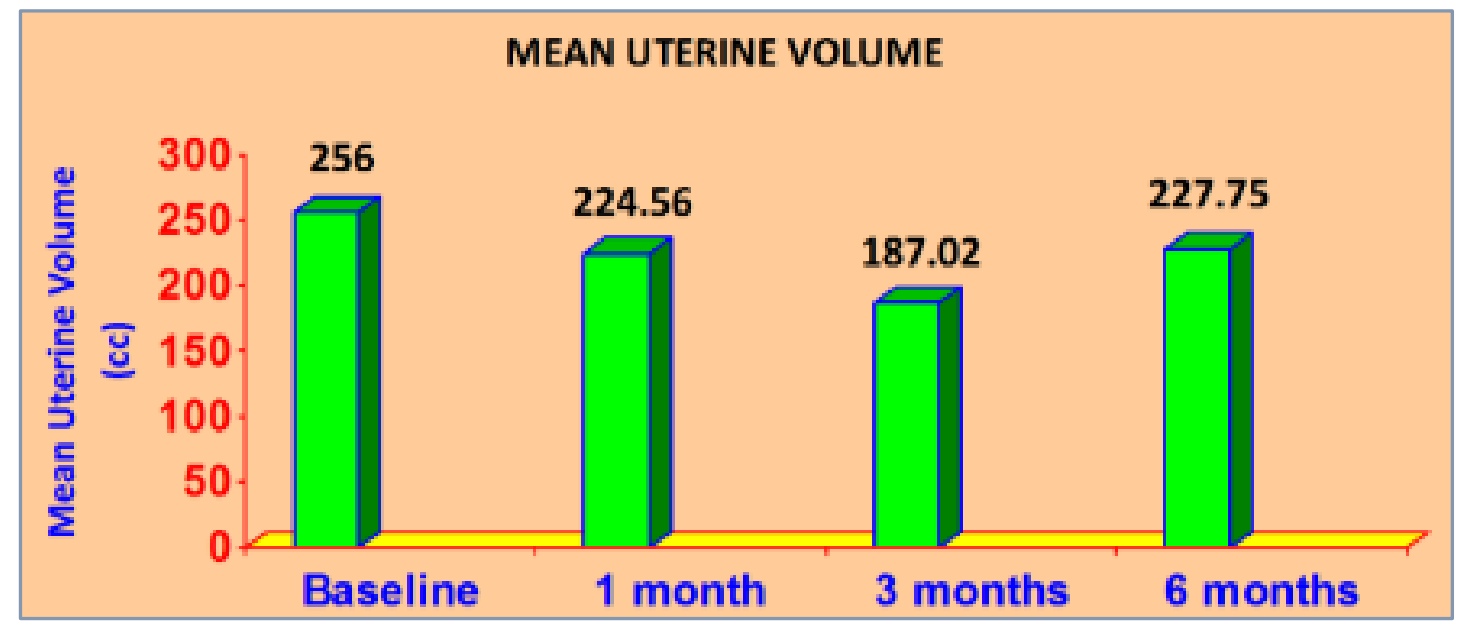

Mean fibroid volume at the beginning of therapy was 139.2cc. Fibroid volume decreased by $14.34 \%(119.52 \mathrm{cc})$ after 1 month, $29.8 \%(97.72 \mathrm{cc})$ after 3 months and 24.98\%(104.42cc) at end of 6 months, as compared to the pre-treatment level. 


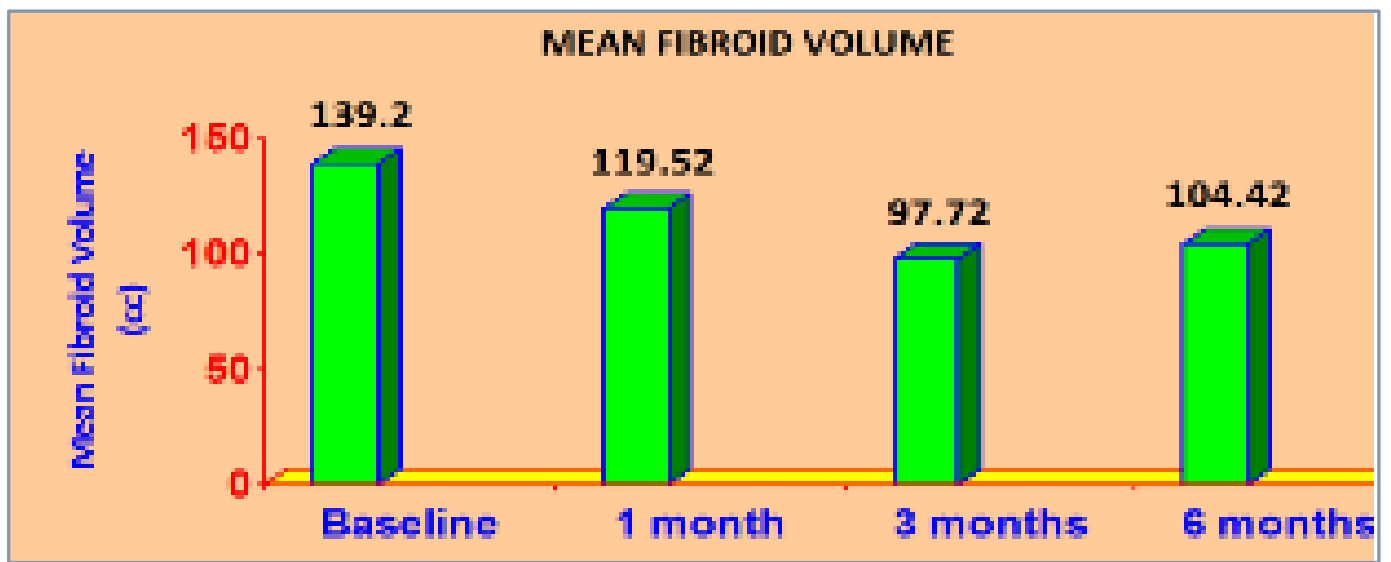

At the end of 3 months, $50 \%$ of patients experienced no side effect. Rest $50 \%$ experienced minor side effects like nausea (8\%), hot flushes (4\%), liver dysfunction as evidenced by mild increase in transaminase (8\%) and simple endometrial hyperplasia in $30 \%$. Follow up of these patients at 6 month i.e., 3 months after stopping the drug does not show any evidence of persistence of these effects.

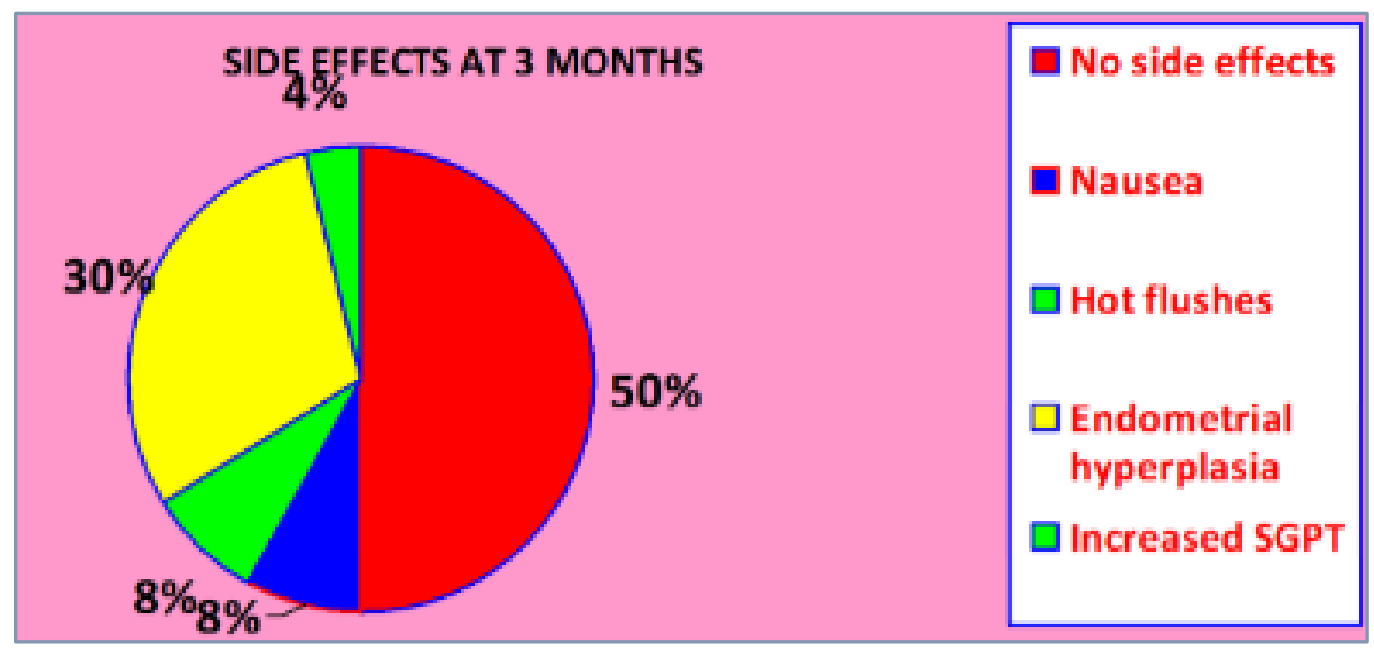

